\title{
About Framing Effect and Its Applications
}

\author{
Haohua Wen ${ }^{1}$
}

\author{
${ }^{1}$ Lancaster University, the UK \\ wenorlando2@gmail.com
}

\begin{abstract}
Framing effects can be used in many fields. Business [1], media [2] and politics are three areas where this effect is often used. Later, I'll show you how the framing effect can be used in each of these three fields.

The simple definition of framing effect is that people respond differently to the same objective fact because of different descriptions. These different responses have a corresponding neural basis, so we think that the framing effect can be traced and studied. More importantly, it is really useful and valuable for us to research framing effect, because this effect can be used in many fields. Business [1] media [2] and politics are three areas where this effect is often used. In this essay, I will show you the neural basis of framing effect and show three applications of this effect that I have collected from a variety of sources. To make it easier for you to understand this effect, examples in this article will be presented in order from simple to complex.
\end{abstract}

Keywords: Framing effect, neural basis, application, easy understanding way.

\section{INTRODUCTION}

Framing effect, as a cognitive bias, was proposed by Amos Nathan Tversky and Daniel Kahneman in the twentieth century [3], and has been continuously developed and applied in a variety of fields until now [4].

The decision maker will consider what "decision frame" to accept through the way of question expression and other factors including norms, habits and personal characteristics.

Meanwhile, the conception that is related to the choice that people make is what we call "decision frame" [5].

By showing how the framing effect works in three common areas of People's Daily life, my article aims to explain how the framing effect affects people's lives in an easy understanding way.

Post reading, I hope reader can realize that framing effect is important and everywhere.

\section{CORRESPONDING NEURAL BASIS}

People would have different judgements because of different descriptions when answering the same question. We can find out the corresponding neural basis to support this phenomenon, and some studies can provide preliminary evidence for us to refer.
For example, in terms of framing losses or gains, a large number of neuroscience studies have found that the nerves related to gain are ventral striatum, anterior cingulate gyrus (ACC), Dorsal striatum and ventromedial prefrontal cortex (VMPFC). Nerves associated with loss are ACC, Amygdala, and dorsal striatum [6].

\section{APPLICATIONS}

In this part, I will show you three applications.

\subsection{APPLICATION 1: In this part, I'll show you some of the uses of framing effect in the business world}

In terms of Business, let's start with a simple example about consumer behavior. In a gasoline station A, gasoline costs $\$ 5.6$ per liter, but you get A discount of $\$ 0.6$ per liter if you pay in cash. At station B, it costs $\$ 5.00$ per liter, but it costs $\$ 0.60$ more if you pay by credit card.

Obviously, the economic cost of buying gasoline from any gas station is the same. But most people think that gas station $\mathrm{A}$ is more attractive than gas station $\mathrm{B}$.

Because the psychological discomfort associated with buying gasoline from station $\mathrm{A}$ is less than the psychological discomfort associated with buying gasoline from station B. Gas station A is associated with 
A "gain" (with A discount), while gas station B is associated with A "loss" (with A price increase) [7].

The reason for the discrepancy, the study found, is that when measuring a trade, people put far more weight on "losses" than on comparable "gains". The happiness of making money is far less than the sadness of losing money. This phenomenon is called "loss aversion". [5].

Therefore, when pricing or promotion is carried out, enterprises should associate it with "profit" rather than "loss", so as to effectively stimulate consumers' purchase behavior. In this case, the framing effect is applied to business area.

Except for gain and loss framing, many types of framing approaches have been identified, including attribute framing (e. g. customers would choose a meat that is $95 \%$ lean rather than $5 \%$ fat), goal framing (e. g. giving a choice between motivating people by offering 5 dollar's reward and levying 5 dollar's fine) and risky choice framing [4], these approaches also can be used in consumer behavior and business field.

For example, when customers see slogan in one online store saying that the person who finds the fake goods can get the compensation of 10 times the retail price. Analogously, the other store claim that no fake would be sold, because they have a qualified brand. Under the same information with different descriptions, which online store will customers choose [8]?

\subsection{APPLICATION 2: Let's see how frames effect human through the media}

In this section, we focus on the application of framing effects in terms of media. Two cases related to media area will be shown as follow, and in these cases, we can clearly see how the media use different descriptions for guiding people being influence by framing effect.

In German-speaking countries, when media report news about suicide, the neutral word Suizid (suicide) is recommended by psychological experts.

On contrast, Freitod ("free death") and Selbstmord ("self-murder") convey relative meanings connected with negative concepts such as free will (Freitod) and crime/murder (Selbstmord), and are therefore not recommended.

For proving this recommendation, experts did an experiment. They used a web-based randomized controlled trial with German speakers, and try to figure out whether the news media's use of Suizid, Selbstmord, and Freitod causes framing effects.

In this questionnaire, participants read identical news reports about suicide, but the specific suicide referents varied. After reading, participants asked to write short summaries of the news reports, to finish a word-fragment completion test and a to complete questionnaire about suicide-related attitudes.

As a result, experts found that participants who read the frame related to free will showed greater attitudinal support for the suicide of patients with incurable illnesses. This study shows the importance of how the news media write about suicide, and also highlights that framing effect plays an important role in the field of media [9].

Another example also shows the influence of framing effect on media. In 2012, an experimental study ( $\mathrm{N}=$ 1,537) was conducted in the Netherlands. In this experiment, scholars analyzed how news framing affects opinions.

The results show that the framing is influenced by the importance of belief and the content of belief, and the content of belief has more significant influence. The effectiveness of each process depends on one's level of political knowledge.

Knowledge type individuals are more affected by the change of belief content and belief importance [10].

\subsection{APPLICATION 3: There is a long history that disseminator chooses to place the focus in particular messages to influence some political events [11]}

In terms of politics, one of the framing uses is that the governments are trying to use this effect to make their policies better implemented by citizens. Later on, I will introduce you an experiment which is complex and related to Covid-19.

The result of this experiment can be used for government to figure out what is the most effective way to appeal to citizens. What's more, an experiment of public good will be provided as well.

The purpose of this study was to test the role of the information framing for effective communication of selfcare behaviors during the COVID-19 pandemic.

From April $19^{\text {th }}$ to $28^{\text {th }} 2020$, expert designed questionnaires toward 319 participants by using gain frame and loss frame, and "the dependent variables were: intention of self- care behaviors, perceived efficacy to motivate others perform self-care behaviors, perceived risk, and perceived." [12]

The result of this research is that gain framing information is more effective in motivating self-care behavior, while loss framing information is more effective in raising the awareness of the risk of contagion [12].

In 1999, Marc Willinger and Anthony Ziegelmeyer in University Louis Pasteur designed an experiment. In this experiment, each participant was randomly assigned to a group of four for 15 sessions. 
At the beginning of each stage, each participant is given 20 tokens, they were asked to allocate between private and public activities.

This game has a dominant strategy equilibrium, that is each participant contribution to public activities 7 tokens, which is the only subgame perfect equilibrium. We studied two approaches.

In positive treatment, each token invested in a public good produces a consistent return for each member of the group. In the negative treatment, each token invested in a private activity causes a loss to other members of the group.

The result of this game is that the value of positive treatment is much higher than the one of negative treatment, subjects contribute less to the public good when they realize the actions of others as a negative externality rather than a positive externality [13].

\section{CONCLUSION AND DISCUSSION}

The underlying logic of the framing effect comes from the workings of the human brain, which are the result of human beings' evolution.

Because of this, decision making will be affected by the framing effect very easily, on the contrary, be rational is difficult. Therefore, framing effect is useful in many fields, especially in business, media and politics.

And with the development of science and technology and society, more and more new fields appear. The application of framing effect in these new fields will be the direction of future research.

At the same time, how to fight against the framing effect and make people keep rational under framing effect is the future research direction as well.

I should make a statement here that people tend to think of psychology as just a patch to Rational Choice Models.

For example, in the field of behavioral economics, people consider that rational behavior will be explained by economics and irrational behavior will be explained by psychology until everything can be explained.

However, the labels rational and irrational imply desirability and undesirability, respectively, in many fields.

Being labeled irrational can lead us to underestimate the importance of psychology in such fields. That is why experts in many fields, such as professor Richard Taylor, the Nobel Prize winner in economics, are reluctant to be labeled irrational [14].

Therefore, although I mentioned that maintaining people's rationality under the frame effect is one of the directions of future research, it does not mean that the research on "decision frame" is only to study people's irrational behavior.

Since framing effect have its own right to be regarded as important and applicable, I think I can safely deduce that framing effect can be used to fight against framing effect itself, though this deduction is still very vague in my mind.

When decision makers frequently think about how language can affect people's decisions, it may also be valuable for makers to think about how language can affect their own decisions.

In order to distinguish the effects of different frames on people in a more detailed way, future research on the definition of frames should shift from equivalence frames to emphasis frames [15].

\section{REFERENCES}

[1]Jennifer A. Howard-Grenville and Andrew J. Hoffman. (2003) The importance of cultural framing to the success of social initiatives in business.

[2]Azadeh A. (2017) Mdeia Framing Effects When is the "tweeorism" label used.

[3]Kahneman, D., \& Tversky, A. (1979) Prospect theory: An analysis of decision under risk. Econometrica, 47, pp. 263-291.

[4]Levin, I. P., Schneider, S. L., \& Gaeth, G. J. (1998) All frames are not created equal: A typology and critical analysis of framing effects. Organizational Behavior and Human Decision Processes, 76, pp. 149-188.

[5]Kahneman, D., and Tversky, A. (1981) The framing of decisions and the psychology of choice, Science.

[6]Luo, H.B., Xu, F.M., Li, B., et al. (2014) The neural mechanism of framing effect. Psychological Science.

[7]Bazerman, M.H. and Moore, D.A., (2008) Judgment in Managerial Decision Making. New York: Wiley.

[8]Li, x., and Ling, W. (2015) Open Journal of Business and Management.

[9]Arendt, F., Scherr, S., Niederkrotenthaler, T., and Till, B. (2018) The role of language in suicide reporting: Investigating the influence of problematic suicide referents. Social Science \& Medicine, 208, pp.165171.

[10]Lecheler, S., and Claes H. de V. (2012) News Framing and Public Opinion: A Mediation Analysis of Framing Effects on Political Attitudes.

[11]Busby, E., Flynn, D. J., \& Druckman, J. N.(2018) Studying framing effects on political preferences: Existing research and lingering questions. 
[12]Gantiva, C., Jiménez-Leal, W. and Urriago-Rayo, J. (2021) Framing Messages to Deal With the COVID19 Crisis: The Role of Loss/Gain Frames and Content. Frontiers in Psychology, 12.

[13]Willinger, M., and Ziegelmeyer, A. (1999) Framing and cooperation in public good games: an experiment with an interior solution.

[14]Lee, E. (2017) Behavioral science, Rationality and Public Policy. DOI: https://www.behavioraleconomics.com/behavioural -science-rationality-and-public-policy.

[15]Claes H. de V., Hajo G. B., and Holli A. S. (2011) (In)direct Framing Effects: The Effects of News Media Framing on Public Support for Turkish Membership in the European Union. 